\title{
Synthesis, Characterisation and Catalytic Behaviour of NiO Nanoflowers for the Photo Degradation of Norflaxacin in Aqueous Medium
}

\author{
L. PARIMALA* and J. SANTHANALAKSHMI
}

Department of Physical Chemistry, University of Madras, Chennai-60025, India

*Department of Chemistry, Annai Violet Arts and Science College, Chennai-600053, India

parimala2255@gmail.com

Received 20 March 2018 / Accepted 3 April 2018

\begin{abstract}
NiO}$ nanoparticles stabilized with starch was synthesized and characterized using UV-Vis, FT-IR, FESEM and XRD techniques. From FESEM analysis the morphology of the prepared $\mathrm{NiO}$ nanoparticles was found to be flower shaped. XRD analysis showed that the NiO nanoparticles corresponds to phase pure cubic crystals and from scherer formula the particle size was calculated to be $9 \pm 0.5 \mathrm{~nm}$. Using optical absorption spectra, tha band gap energy was obtained. Photocatalytic activity of the synthesized nanoparticles was investigated by carrying out the degradation studies of norfloxacin under UV light irradiation.
\end{abstract}

Keywords: NiO nanoparticles, Starch, Degradation, Norfloxacin, pH studies

\section{Introduction}

For the few decades, number of studies have been focussed on the degradation of toxic organic compounds in waste water ${ }^{1-10}$. Pharmaceuticals such as antibiotics enter the water system through human, agricultural and veterinary practices ${ }^{11-13}$. Because of its widespread use and poor biodegradability, these drugs get accumulated in the aquatic environment causing adverse effects on the aquatic organisms. Norfloxacin(NF) is a fluoroquinolones class of antibiotic used in the treatment of urinary tract infections. NF has polar structure and therefore not sorbed in subsoil and leached significantly into water resources. Numerous methods are available in the literature for the treatment of waste water ${ }^{14-17}$. However, recently semiconducting material has attracted much attention in treating waste water containing pharmaceuticals ${ }^{18-20}$.

$\mathrm{NiO}$ nanoparticles have been studied extensively for their optical, electronic, magnetic, thermal and mechanical properties and potential application in catalyst, gas sensors and photo-electronic devices ${ }^{21-25}$. $\mathrm{NiO}$ has played important role in catalysis and as $p$-type semiconductor. Recently Gondal et al., used $\mathrm{NiO}$ nanoparticles in the photocatalytic degradation of phenol ${ }^{26}$. Among the different methods reported for the synthesis of NiO 
nanoparticles such as evaporation, sputtering, electrodeposition and sol gel techniques ${ }^{27-31}$, solgel technique is more advantageous than other techniques since the chemical and physical properties of the nanomaterials can be tunned suitably by adjusting the operational parameters. In the present work, we have synthesized $\mathrm{NiO}$ nanoparticles with biostabilizer starch and used for the photocatalytic degradation of the antibiotic NF. The as prepared NiO nanoparticles are characterized using FESEM, UV-Vis, FT-IR and XRD measurements. Progress of the photo degradation of $\mathrm{NF}$ in the presence of $\mathrm{NiO}$ nanoparticles was monitored by using time dependant UV-Vis spectra. The reaction followed pseudo first order kinetics. Rate coefficient values at different $\mathrm{pH}$ and the optimum $\mathrm{pH}$ for degradation of $\mathrm{NF}$ was determined.

\section{Experimental}

Norfloxacin was purchased from Fluka Co. Ltd. Triple distilled water was used for solution preparations. $\mathrm{NiCl}_{2} .6 \mathrm{H}_{2} \mathrm{O}, \mathrm{NaOH}$ and $\mathrm{pH}$ buffer tablets are purchased from SRL, India ltd. Starch belong to the Fischer chemicals India Ltd. All working solutions are freshly prepared. UV-Vis spectrometer, double beam, Techcom with $1 \mathrm{~cm}$ path length quartz cuvettes was used. Bruker tensor 27 instrument was used for FT-IR measurements. Bruker D8 advance diffractometer was used for XRD data. FESEM of the nanoparticles were measured using SU6600, HITACHI model operating at an accelerating voltage of $100 \mathrm{KV}$.

\section{Synthesis of $\mathrm{NiO}$ nanoflowers and its characterization}

$3 \mathrm{~g}$ of the stabilizer starch was added to $200 \mathrm{~mL}$ ethanol. The mixture was heated at $40{ }^{\circ} \mathrm{C}$ for about $10 \mathrm{~min}$ with constant stirring for dissolution of the stabilizer. $\mathrm{NiCl}_{2} \cdot 6 \mathrm{H}_{2} \mathrm{O}(1.0 \mathrm{~g})$ was added to the solution, which was then heated at $50{ }^{\circ} \mathrm{C}$ under nitrogen purging. $0.1 \mathrm{M}$ $\mathrm{NaOH}$ solution was added drop wise and the $\mathrm{pH}$ of the final mixture was controlled in the range of $10-11$. The mixtures were held at $50{ }^{\circ} \mathrm{C}$ for $2 \mathrm{~h}$ and green gel was obtained. The gel was washed several times using triple distilled water to remove by-products and excess stabilisers. The obtained gel was heated at $200{ }^{\circ} \mathrm{C}$ for $1 \mathrm{~h}$. A black powder was formed and subjected to FESEM, UV-VIS, FT- IR and XRD characterization.

\section{Photodegradation studies}

Photocatalytic activity of the as prepared $\mathrm{NiO}$ nanoparticles were evaluated by studying the photodegradation of $\mathrm{NF}$ using $\mathrm{NiO}$ nanoparticles under UV light. Photodegradation experiments were carried out with a solution of $10 \mathrm{mg} / \mathrm{L}$ of $\mathrm{NiO} \mathrm{nps}$ and $50 \mathrm{mg} / \mathrm{L}$ of NF . The mixture was then exposed to UV light of $365 \mathrm{~nm}$ wavelength from xenon lamp for variable time intervals. The change in absorption spectrum of NF was recorded for different UV irradiation time.

\section{Results and Discussion}

\section{Structure characterisation}

Figure 1 gives the XRD pattern of $\mathrm{NiO}$ nps stabilised with the biopolymer starch. All the diffraction peaks may be assigned to pure cubic $\mathrm{NiO}$ phase which is in agreement with the reported value (JCPDS 47-1049) readily indexed as (111), (200) and (220) crystal planes ${ }^{32,33}$. No impurity peaks were detected which confirms the formation of phase pure $\mathrm{NiO} \mathrm{nps}$. Using Debye-Scherrer equation, the average size of the $\mathrm{NiO}$ nps was found to be $9 \pm 0.5 \mathrm{~nm}$.

FESEM was used to study the morphology of the NiO nanoparticles. FESEM image was given in Figure 2b, which shows the formation of NiO nanoflowers. FT-IR spectrum of pure starch and $\mathrm{NiO}$ nps stabilized with starch were shown in Figure 3. Pure starch shows peaks at $3351 \mathrm{~cm}^{-1}, 2928 \mathrm{~cm}^{-1}, 1645 \mathrm{~cm}^{-1}$ corresponding to $-\mathrm{OH}, \mathrm{C}-\mathrm{H}$ and $>\mathrm{C}=\mathrm{O}$ stretching 
frequencies which are completely vanished in the $\mathrm{NiO} \mathrm{np}$ spectrum. The prominent peaks at $1400 \mathrm{~cm}^{-1}$ to $575 \mathrm{~cm}^{-1}$ are completely diminished in the nano particle spectrum. There is a peak at $528 \mathrm{~cm}^{-1}$ corresponding to $\mathrm{NiO}$. The FT-IR spectrum of NiOnp confirms the binding of starch to the np. In the NiOnp surface, strong H-bonding interactions hold the $\mathrm{OH}$ groups of the stabilizing agent, starch.

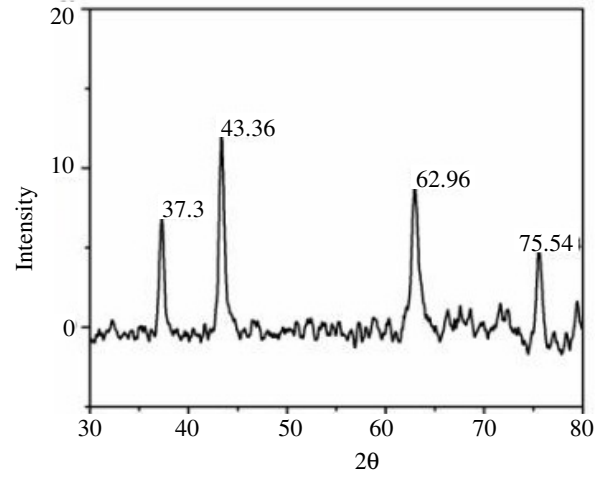

Figure 1. XRD pattern of $\mathrm{NiO}$ nps
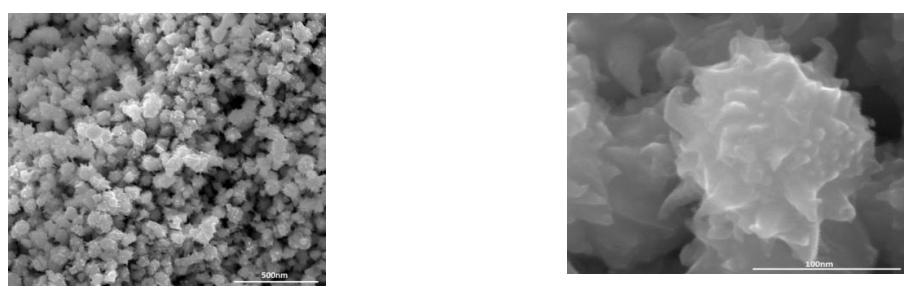

Figure 2a. FESEM image of $\mathrm{NiO}$ nps $\quad$ Figure 2b. FESEM image of $\mathrm{NiO}$ nps

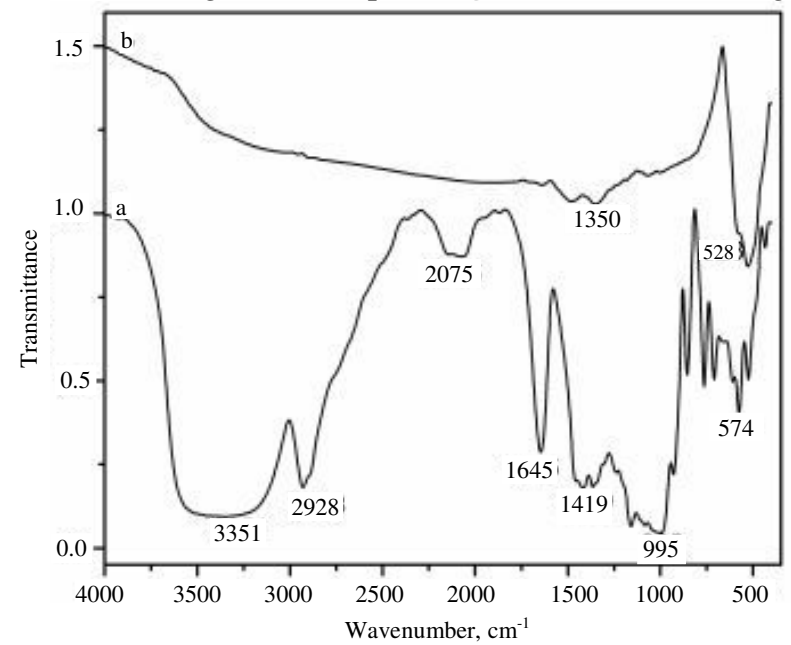

Figure 3. FT-IR spectrum of pure starch and $\mathrm{NiO}$ nps stabilized with starch

Figure 4 shows the optical absorption spectrum of the NiO nps. The absorption band gap $\mathrm{E}_{\mathrm{g}}$ can be calculated by the following equation:

$$
(\alpha h v)^{\mathrm{n}}=\mathrm{B}(\mathrm{h} v-\mathrm{Eg})
$$


In which $\mathrm{h} v$ is the photo energy, $\alpha$ is the absorption coefficient, $\mathrm{B}$ is a constant relative to the material and $\mathrm{n}$ is either 2 for a direct transition or $1 / 2$ for an indirect transition. Eg can be calculated as shown in Figure $4 b$, by plotting $(\alpha h v)^{2}$ versus photon energy and extrapolating the linear portion of the curve to the photon energy axis. The direct band gap of the prepared $\mathrm{NiO}$ nps was found to be $3.2 \mathrm{eV}^{34}$.
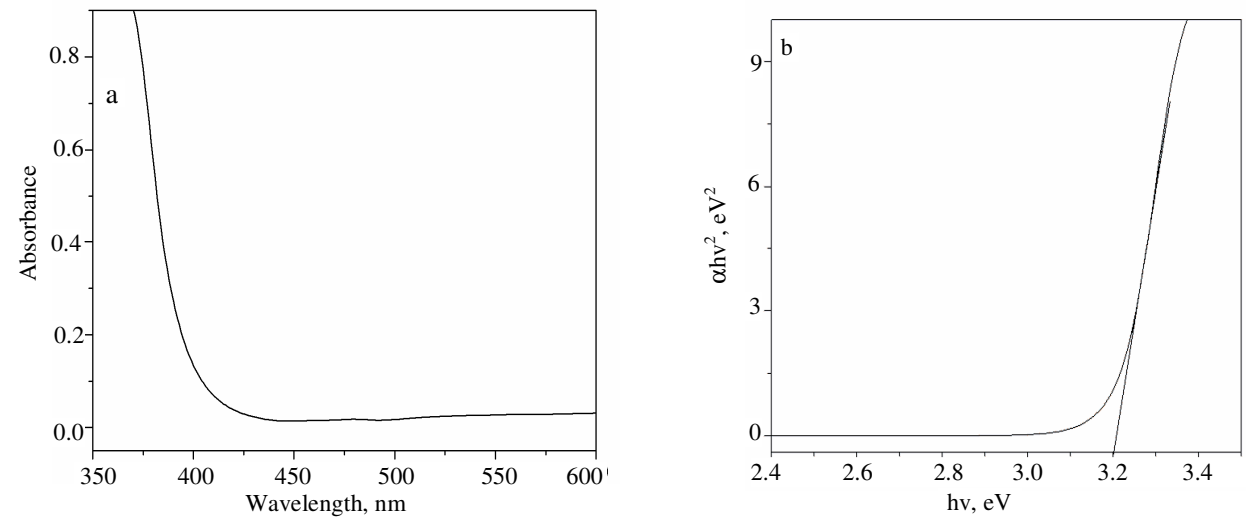

Figure 4. Optical absorption spectrum of the $\mathrm{NiO}$ nps

\section{Photocatalytic activity of $\mathrm{NiO}$ nps}

Figure 5 shows UV spectra of NF at various time intervals after irradiation. Absorbance at $\lambda_{\max }(272 \mathrm{~nm})$ significantly decreased showing the degradation of NF. In order to confirm the photocatalytic activity of $\mathrm{NiO}$ nps, the sample was irradiated with UV light without $\mathrm{NiO}$ nps for $30 \mathrm{mins}$ at $5 \mathrm{~min}$ increments. There is no appreciable decrease in absorbance at $\lambda_{\max }$ during direct photolysis of NF. Photodegradation of NF in the presence of $\mathrm{NiO} n$ ps follows first order kinetics. The absorbance versus irradiation time plots determined from the spectra is shown in Figure 6. It may be seen that a gradual exponential decrease in the absorbance values with time are found out. The pseudo first order rate coefficient values for the degradation are determined from the kinetic plots which are obtained by plotting $\log \left(\mathrm{OD}_{0} / \mathrm{OD}_{\mathrm{t}}\right)$ versus irradiation time.

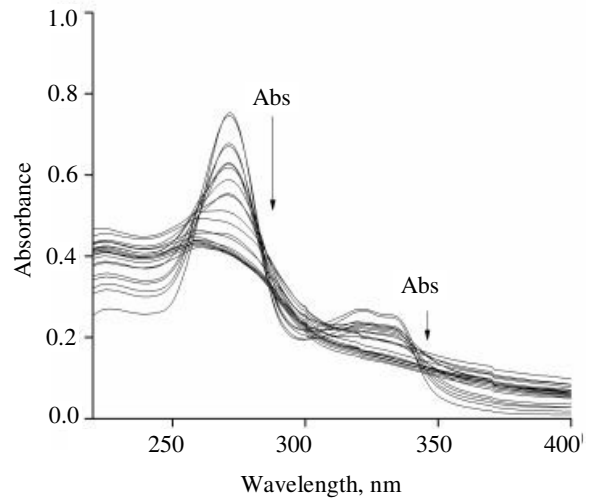

Figure 5. UV spectra of NF at various time intervals

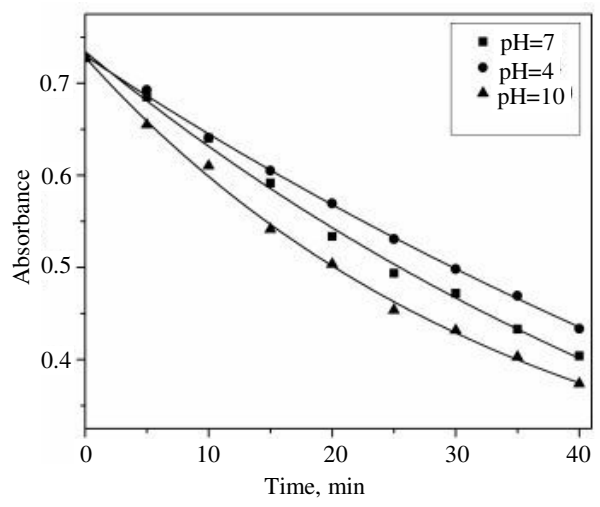

Figure 6. Absorbance versus irradiation time plot for the photodegradation of $\mathrm{NF}$ in the presence of NiOnps at various $\mathrm{pH}$ 
Effect of $\mathrm{pH}$ on the catalytic activity of $\mathrm{NiO}$ nps was examined by adjusting $\mathrm{pH}$ of the reaction mixture at the values of 4,7 and 10 . Kinetic plots for different $\mathrm{pH}$ values of the reaction mixture were given in Figure 7 and the corresponding rate coefficient values are determined. From the $\mathrm{k}$ values, it is evident that the degradation rate is maximum in alkaline medium, shown in Figure 8.

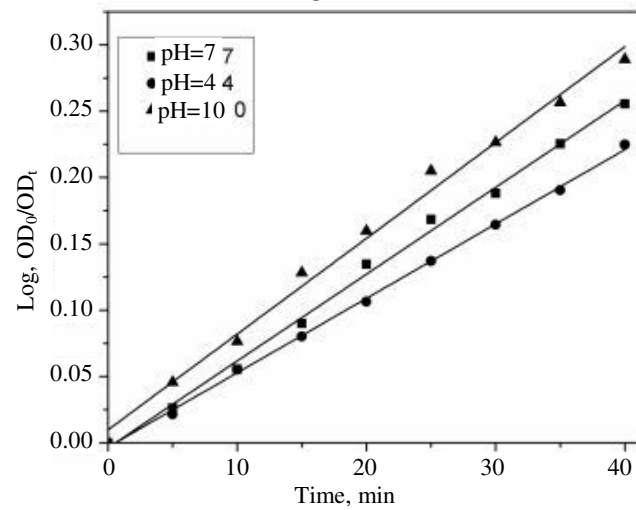

Figure 7. Kinetic plot for the photodegradation of NF in the presence of NiOnps at various $\mathrm{pH}$

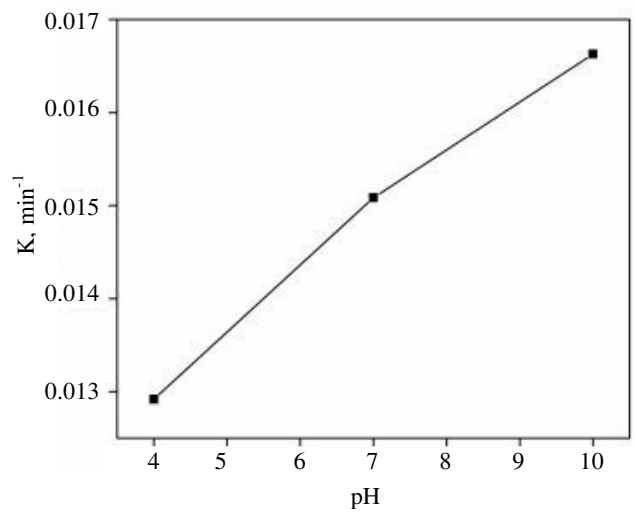

Figure 8. pH versus k plot for photodegradation of $\mathrm{NF}$ at various $\mathrm{pH}$

Chemical structure of the drug and surface charge properties are strongly dependent on the $\mathrm{pH}$ of the reaction medium. NF has $\mathrm{pKa}$ values $^{18}$ at 6.34 and 8.75 corresponding to proton dissociation from carboxyl group and proton combination to $\mathrm{N}$ in the piperazinyl group respectively. Under different $\mathrm{pH}$ conditions, $(\mathrm{pH}=4,7$ and 10) NF exists as positively charged, zwitter ionic and negatively charged. It is well documented that adsorption of reactants on the surface of catalyst is the basic step in photocatalytic reaction ${ }^{18}$. At the acidic $\mathrm{pH}$, both the $\mathrm{NiO}$ nps and NF molecule are positively charged repelling each other resulting in low reaction rate. When the $\mathrm{pH}$ is between the $\mathrm{pKa}$ values, $\mathrm{NF}$ is in zwitter ionic form whereas $\mathrm{NiO}$ is negatively charged. Positively charged $\mathrm{N}$ atom of peperazinyl ring bound with the negatively charged $\mathrm{NiO}$ nps promotes the reaction resulting in increase of rate of the reaction. At the basic $\mathrm{pH}$, optimal $\mathrm{NF}$ decay was observed. This may be due to higher concentration of hydroxyl ions resulting in more hydroxyl radicals. Further increase of $\mathrm{pH}$ decreases the rate of the reaction because both $\mathrm{NF}$ and NiOnps are negatively charged repelling each other retarding the reaction.

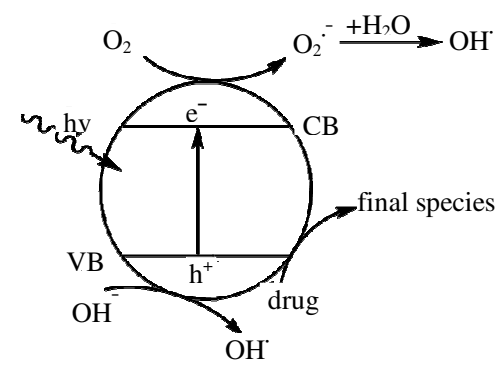

$\mathrm{NiO}+\mathrm{hv} \rightarrow \mathrm{h}_{\mathrm{VB}}{ }^{+}+\mathrm{e}_{\mathrm{CB}}{ }^{-} \mathrm{h}_{\mathrm{VB}}{ }^{+}+\mathrm{H}_{2} \mathrm{O} \rightarrow \mathrm{OH}^{-} \mathrm{e}_{\mathrm{CB}}{ }^{-}+\mathrm{O}_{2} \rightarrow \mathrm{O}_{2}{ }^{-}+\mathrm{H}_{2} \mathrm{O} \rightarrow \mathrm{OH}^{*}$ Drug $+\mathrm{h}_{\mathrm{VB}}+\rightarrow$ mineralisation

Scheme 1. Proposed mechanism of drug degradation in the presence of $\mathrm{NiO}$ nanoparticles 
It is evident from the earlier reports ${ }^{35,36}$ that on irradiation of UV light, the metal oxide nanoparticles generate an excitation of electron from conduction band to valence band leading to electron hole formation. Transfer of generated electron to NF adsorbed on the $\mathrm{NiO}$ nanoparticle surface can be considered as the first step of photocatalytic degradation of NF. The photogenerated hole and hydroxyl radicals further acts on the drug NF leading to mineralization of the drug. The proposed mechanism of drug degradation in the presence of $\mathrm{NiO}$ nanoparticles is given in Scheme 1 .

\section{Conclusion}

$\mathrm{NiO}$ nps stabilised with starch was prepared and characterized using UV-Vis, FT-IR, FESEM and XRD analysis. The band gap energy for the as prepared $\mathrm{NiO}$ nanoparticles was $3.2 \mathrm{eV}$. The average size of the particles was found to be $10 \pm 1 \mathrm{~nm}$. Photocatalytic activity of starch bound $\mathrm{NiO}$ nps was investigated for degradation studies of the drug NF. UV-Vis spectra was used to follow the degradation reaction. Kinetic plots were drawn and the rate coefficient values are determined. $\mathrm{pH}$ effect on drug degradation was studied and optimum $\mathrm{pH}$ was found to be 10 . Thus, the biopolymer starch stabilised $\mathrm{NiO}$ nps were found to be efficient photocatalyst in the drug degradation. The results are encouraging and further studies can be carried out in drug waste water treatment using $\mathrm{NiO}$ nps as photocatalyst.

\section{References}

1. Andreas Haarstrick, Oemer M Kut and Elmar Heinzle, Environ Sci Technol., 1996, 30(3), 817-824; DOI:10.1021/es9502278

2. Hoffmann M R, Martin S T, Choi W and Bahanmann D W, Chem Rev., 1995, 95(1), 69-96; DOI:10.1021/cr00033a004

3. Mills A and Hunte S L, J Photochem Photobiol A: Chem., 1997, 108(1), 1-35; DOI:10.1016/S1010-6030(97)00118-4

4. Hermann J M, Catal Today, 1999, 53(4), 115-129; DOI:10.1016/S09205861(99)00107-8

5. Litter M I, Appl Catal B: Environ., 1999, 23(2-3), 89-114; DOI:10.1016/S09263373(99)00069-7

6. Fujishima A, Rao T N and Tryk D A, J Photochem Photobiol C: Photochem Rev., 2000, 1(1), 1-21; DOI:10.1016/S1389-5567(00)00002-2

7. Khataeea A R and Kasiri M B, J Mol Catal A, 2010, 328(1-2), 8-26; DOI:10.1016/j.molcata.2010.05.023

8. $\quad$ Dong Y, He K, Yin L and Zhang A, Nanotechnology, 2007, 18(43), 435602.

9. Wu ZC, Zhanga Y, Tao TX, Zhang L and Fong H, Appl Surf Sci., 2010, 257(3), 10921097; DOI:10.1016/j.apsusc.2010.08.022

10. Yousef A, Barakatc N A M, Amnaa T, Unnithana A R, Al Deyab S S and Kima H Y, J Lumin., 2012, 132(7), 1668-1677; DOI:10.1016/j.jlumin.2012.02.031

11. Hernando M D, Mezcua M, Ferna'ndez-Alba A R and Barcelo' D, Talanta, 2006, 69(2), 334-342; DOI:10.1016/j.talanta.2005.09.037

12. Ku"mmerer K, Chemosphere, 2001, 45(6-7), 957-969; DOI:10.1016/S00456535(01)00144-8

13. Kummerer K, Chemosphere, 2009, 75(4), 417-434; DOI:10.1016/j.chemosphere.2008.11.086

14. Kiran A Thabaj, Suresh D Kulkarni, Shivamurti A Chimatadar and Sharanappa T Nandibewoor, Polyhedron, 2007, 26(17), 4877-4885; DOI:10.1016/j.poly.2007.06.030 
15. An T C, Yang H, Song W H, Li G Y, Luo H Y and Cooper W J, J Phys Chem A, 2010, 114(7), 2569-2575; DOI:10.1021/jp911349y

16. Rivas J, Encinas A, Beltran F and Graham N, J Environ Sci Health A, 2011, 46(9), 944- 951; DOI:10.1080/10934529.2011.586249

17. Wang P, He Y L and Huang C H, Water Res., 2010, 44(20), 5989-5998; DOI:10.1016/j.watres.2010.07.053

18. Meijuan Chen and Wei Chu, Ind Eng Chem Res., 2012, 51(13), 4887-4893; DOI:10.1021/ie300146h

19. Parimala L and Santhanalakshmi J, Reac Kinet Mech Cat., 2014, 111(2), 621-632; DOI:10.1007/s11144-013-0669-8

20. Molinari R, Pirillo F, Loddo V and Palmisano L, Catal Today, 2006, 118(1-2), 205213; DOI:10.1016/j.cattod.2005.11.091

21. Lee W, Jeong M C and Myoung J M, Acta Mater., 2004, 52(13), 3949-3957; DOI:10.1016/j.actamat.2004.05.010

22. Xu C L, Qin D H, Li H, Xu T and Li H L, Mater Lett., 2004, 58(30), 3976-3979; DOI:10.1016/j.matlet.2004.08.026

23. Park W I, Jun Y H, Jung S W and Yi G C, Appl Phys Lett., 2003, 82, 964; DOI:10.1063/1.1544437

24. Takehia F, Satoshi O, Hajime O, Tadashi H and Makio N, J Power Sources, 2000, 86(1-2), 340-346; DOI:10.1016/S0378-7753(99)00416-4

25. Katz J L and Miquel P F, Nanostruct Mater., 1994, 4(5), 551-557; DOI:10.1016/0965-9773(94)90063-9

26. Khizar Hayat, Gondal M A, Mazen M Khaled and Shakeel Ahmed, J Mol Catal A: Chem., 2011, 336(1-2), 64-71; DOI:10.1016/j.molcata.2010.12.011

27. Hotovy I, Huran J, Spiess L, et al., Sens Actuators B: Chem., 1999, 57(1-3), 147-152; DOI:10.1016/S0925-4005(99)00077-5

28. Bi H, Li S D, Zhang Y C and Youwei D, J Magn Magn Mater., 2004, 277(3), $363-$ 367; DOI:10.1016/j.jmmm.2003.11.017

29. Pilban Jahromi S, Huang N M, Muhamad M R and Lim H N, Ceramics International, 2013, 39(4), 3909-3914; DOI:10.1016/j.ceramint.2012.10.237

30. Wang W Z, Liu Y K, Xu C K, Changlin Z and Guanghou W, Chem Phys Lett., 2002, 362(1-2), 119-122; DOI:10.1016/S0009-2614(02)00996-X

31. Wei Z Q, Xia T D, Bai L F, Jun W, Zhiguo W and Pengxun Y, Mater Lett., 2006, 60(6), 766-770; DOI:10.1016/j.matlet.2005.10.008

32. Dharmaraj N, Prabu P, Nagarajan S, Kim C H, Park J H and Kim H Y, Mat Sci Engg B, 2006, 128(1-3), 111-114; DOI:10.1016/j.mseb.2005.11.021

33. Lili Wu, Youshi Wu, Huiying Wei, Yuanchang Shi and Chunxia Hu, Mat Lett., 2004, 58(21), 2700-2703; DOI:10.1016/j.matlet.2004.03.047

34. Xiong Wang, Jimei Song, Lisheng Gao, Jiayi Jin, Huagui Zheng and Zude Zhang, Nanotechnology, 2004, 16(1), 37.

35. Wang Y, in Advances in Photochemistry, in: Neckers D C, Volman D H, G. von B“ unau (Eds.), Wiley, New York, 1995, 179-234.

36. Ohtani B, Kusakabe S, Okada K, Tsuru S, Izawa K, Amino Y and Nishimoto S, Tetrahedron Lett., 1995, 36(18), 3189-3192; DOI:10.1016/0040-4039(95)00509-B 